\title{
ANALISIS KESESUAIAN LAHAN UNTUK BUDIDAYA PERIKANAN PADA LAHAN PESISIR KABUPATEN JEPARA
}

\author{
Arif Mustofa ${ }^{\mathrm{a}, *}$, Decky Rochmanto ${ }^{\mathrm{b}}$ \\ ${ }^{a}$ Budidaya Perairan, Fakultas Sains dan Teknologi, UNISNU \\ ${ }^{\mathrm{b}}$ Teknik Sipil, Fakultas Sains dan Teknologi, UNISNU \\ Jl. Taman Siswa No. 9 Tahunan (Pekeng) Jepara \\ *Koresponden penulis : arifmustofa@unisnu.ac.id
}

\begin{abstract}
Abstrak
Analisis daya dukung lahan terhadap budidaya perikanan sangat penting dilakukan agar usaha budidaya tidak menemukan hambatan. Analisis keseuaian lahan dilakukan dengan melakukan evaluasi karakteristik lahan disesuaikan dengan kriteria hasil penelitian yang telah dilakukan. Tujuan penelitian ini adalah menganalisis dan mengevaluasi kesesuaian lahan pesisir Kabupaten Jepara sebagai lahan budidaya perikanan. Metode penelitian berupa survei dan metode analisis data didasarkan pada kriteria kesesuaian lahan pesisir dimodifikasi dari beberapa sumber peneliti terdahulu. Kriteria tersebut berupa tekstur tanah, kelerengan pantai, tipe pantai, curah hujan, kondisi hidrologi, jalur hijau, $\mathrm{pH}$ tanah dan penutupan lahan. Pengukuran dan pengambilan sampel di titik pengamatan yang berumlah delapan yaitu Kecamatan Kedung, Tahunan, Jepara, Mlonggo, Bangsri, Kembang, Keling dan Donorojo. Analisa data menggunakan scoring dengan tiga tingkatan 100, 90 dan 80 serta hasil total penjumlah skor dengan kriteria daya dukung baik bernilai 91-100, daya dukung sedang bernilai 81-90 dan daya dukung rendah bernilai $\leq 80$. Hasil analisis menunjukkan bahwa wilayah pesisir Kabupaten Jepara yang memiliki karakteristik daya dukung lahan baik terhadap budidaya perikanan adalah wilayah pesisir Kecamatan Kedung, Mlonggo dan Keling. Kriteria daya dukung sedang adalah wilayah pesissir Kecamatan Tahunan, Jepara, Bangsri, Kembang dan Donorojo. Tidak ditemukan kriteria daya dukung lahan rendah di wilayah pesisir Kabupaten Jepara.
\end{abstract}

Kata kunci: kesesuaian, lahan, budidaya, perikanan, Jepara

\begin{abstract}
Alignment of land to determine the carrying capacity of land for aquaculture is very important so that in doing business there are no obstacles. Jepara Regency has 8 sub-districts which have coastal areas. Land suitability analysis is carried out by evaluating the characteristics of the land according to the criteria of the research results that have been carried out. The purpose of this study was to analyze and evaluate the suitability of coastal lands in Jepara Regency for use as aquaculture land. The research method in the form of survey and data analysis method is based on the modified coastal land suitability criteria from several previous research sources. These criteria are soil texture, beach slope, beach type, rainfall, hydrological conditions, green belt, soil $\mathrm{pH}$ and land cover. Measurement and sampling at observation points totaling eight representing the coastal sub-districts in Jepara Regency, namely Kedung, Tahunan, Jepara, Mlonggo, Bangsri, Kembang, Keling and Donorojo Districts. Analysis of the data using three levels of scoring with 100, 90 and 80 and the total score with the criteria of good carrying capacity is $91-100$, medium carrying capacity is $81-90$ and low carrying capacity is $<80$. The results of the analysis show that the coastal area of Jepara Regency which have good carrying capacity characteristics for aquaculture are the coastal areas of Kedung, Mlonggo and Keling Districts. The medium carrying capacity is the coastal area of Tahunan, Jepara, Bangsri, Kembang and Donorojo districts. There are no criteria for low carrying capacity in the coastal area of Jepara Regency.
\end{abstract}

Keywords: carrying, capacity, aquaculture, suitability, Jepara

\section{PENDAHULUAN}

Usaha budidaya yang dikelola oleh masyarakat perlu memperhatikan kondisi lingkungan. Baik lingkungan perairan maupun kondisi wilayah daratan. Keadaan lingkungan perairan yang optimal adalah kondisi yang sesuai dengan persyaratan bagi biota yang dibudidayakan dapat tumbuh dan berkembang dengan baik. Selain itu, lokasi lahan yang tepat 
sangat penting bagi keberhasilan pengelolaan budidaya. Pengelolaan tambak membutuhkan perencanaan yang matang. Jika tidak, justru akan menimbulkan terbengkalainya lahan tambak, baik karena gagal panen akibat kesalahan manajemen yang kurang optimal. Menentukan lokasi tambak jika kurang cermat akan mengakibatkan pemborosan yang sangat besar apalagi ditambah dengan tingkat pengelolaan tambak yang kurang baik. Keadaan ini mempengaruhi tingkat produksinya [11].

Kabupaten Jepara sebagai salah satu kabupaten yang berada di persisir Pulau Jawa, merupakan daerah yang memilii sumberdaya perikanan cukup baik dan potensial dikembangkan guna perikanan budidaya. Data tahun 2013 luas tambak Kabupaten Jepara seluas 909,63 ha menurun dari tahun tahun sebelumnya [5].

Banyak sekali studi yang menyebutkan bahwa kegagalan usaha tambak adalah menurunnya kualitas lingkungan. Kualitas air laut sebagai bahan baku utama usaha tambak mengalami degradasi yang cukup akibat dari aktivitas manusia di daratan. Pada lingkungan darat, pembukaan lahan mangrove untuk lahan tambak justru mengakibatkan menurunnya daya dukung pengelolaan tambak. Ekosistem pesisir yang rusak tidak akan bisa mendukung usaha tambak dan berpotensi menyebabkan kegagalan. Pada sisi lain, pemilihan lokasi tambak yang kurang tepat akan menimbulkan masalah besar. Masalah besar yang dihadapi petambak akibat salah menentukan lokasi budidaya tambak adalah peningkatan biaya konstruksi, operasional budidaya dan munculknya masalah lingkungan [7].

Analisis kesesuaian lahan untuk budidaya tambak perlu dilakukan agar menjadi dasar pertimbangan dalam pengambilan keputusan tetang penggunaan lahan yang cocok dengan kesesuaiannya [9]. Penelitian tentang pemilihan lahan pesisir di Kabupaten Jepara yang sesuai untuk dilgunakan sebagai budidaya perikanan sangat penting. Selain memberikan informasi utama kepada pelaku usaha budidaya juga memberikan sumbangan pengetahuan kepada masyarakat. Penelitian kesesuaian lahan bertujuan untuk menganalisis dan mengevaluasi kesesuaian lahan pesisir Kabupaten Jepara untuk digunakan sebagai lahan budidaya perikanan.

\section{METODE}

Metode penelitian menggunakan metode survey dengan mengumpulkan sejumlah besar data yang diperoleh secara bersamaan. Data utama adalah tekstur tanah, kelerengan pantai, tipe pantai, kondisi hidrologi, jalur hijau, $\mathrm{pH}$ tanah dan penutupan lahan. Sedangkan data pendukung adalah peta rupa bumi dan data curah hujan.

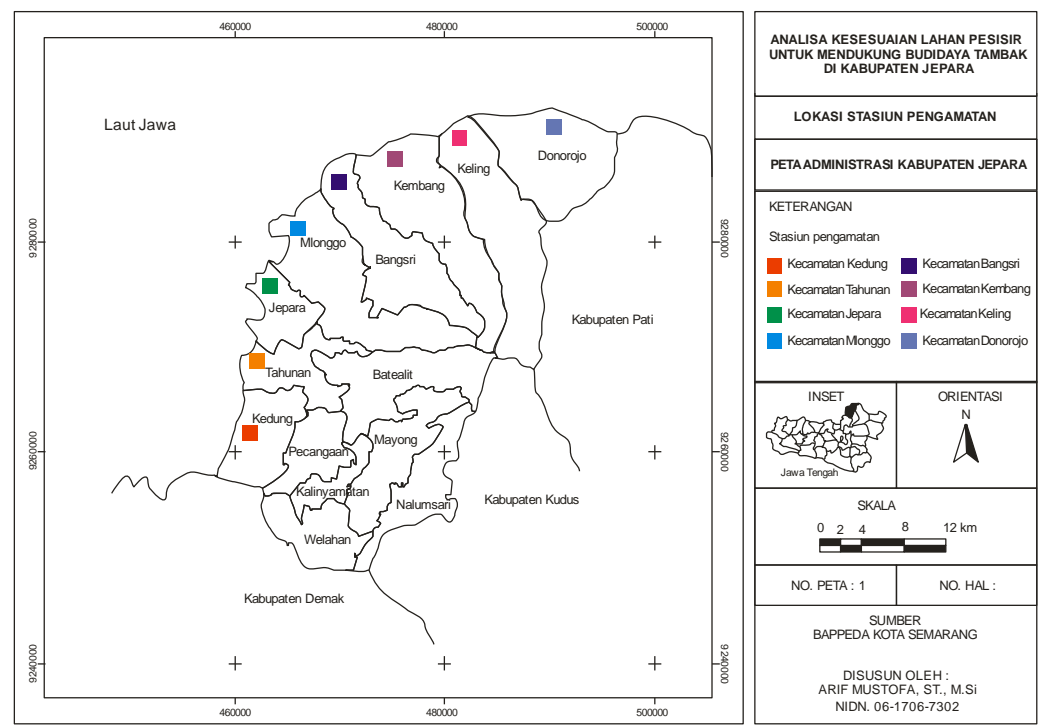

Gambar 1. Lokasi stasiun pengamatan di sepanjang pantai Kabupaten Jepara 
Penelitian dilaksanakan pada bulan Mei Juli 2020 dengan lokasi di pesisir Kabupaten Jepara. Stasiun pengamatan didasarkan keterwakilan wilayah yang memiliki pesisir di kecamatan se-Kabupaten Jepara. Stasiun pengamatan tersebut adalah Kecamatan Kedung, Tahunan, Jepara, Mlonggo, Bangsri, Kembang, Keling dan Donorojo. Adapun peta stasiun pengamatan sebagaimana dalam Gambar 1.

Alat dan bahan yang diperlukan untuk penelitian ini adalah GPS, theodolit, meteran tanah, botol sampel tanah dan kamera digital. Bahan pendukungnya adalah literatur-literatur serta peta administrasi Kabupaten Jepara.

Pengukuran parameter terhadap sampel di lokasi penelitian untuk mendapatkan data utama. Pengambilan sampel dengan metode purposive sampling yang mendasarkan pada faktor karakteristik unit analisis. Parameter penelitian adalah tekstur tanah, kelerengan pantai, tipe pantai, curah hujan, kondisi hidrologi, jalur hijau, $\mathrm{pH}$ tanah dan penutupan lahan. Analisa tekstur dan $\mathrm{pH}$ tanah dilakukan di laboratorium. Sedangkan kelerengan tanah, jalur hijau, tipe pantai, kondisi hidrologi dan penutupan lahan diukur dan diamati secara langsung di lapangan. Data curah hujan menggunakan data dari BMKG untuk wilayah penelitian.

Analisa daya dukung menggunakan metode analisa data yang didasarkan pada pendapat beberapa ahli dengan memberikan skor pada tiap parameter sesuai dengan karakteristik masing-masing. Hasil penelitian Poernomo tahun 2011 tentang identifikasi dan inventarisasi potensi lahan pesisir serta penelitian Ristiyani tahun 2012 tentang evaluasi kesesuaian lahan untuk budidaya tambak menggunakan metode scoring terhadap parameter kualitas lahan. Karakteristik dari masing-masing parameter sesuai dengan lokasi pengamatan dan skor daya dukung disajikan dalam tabel berikut.

Tabel 1. Karakteristik parameter dan skor daya dukung

\begin{tabular}{|c|c|c|c|c|}
\hline \multirow{2}{*}{ No. } & \multirow{2}{*}{ Parameter } & \multicolumn{3}{|c|}{ Skor daya dukung } \\
\hline & & 100 & 90 & 80 \\
\hline 1 & Tekstur tanah & Lempung liat berpasir & Lempung berpasir & Liat berdebu \\
\hline 2 & Kelerengan pantai & $>8 \%$ & $3-8 \%$ & $<3 \%$ \\
\hline 3 & Tipe pantai & $\begin{array}{l}\text { Sangat landai, teluk, } \\
\text { berlumpur, laguna }\end{array}$ & $\begin{array}{l}\text { Landai, karang, } \\
\text { berpasir, sedikit } \\
\text { berlumpur, terbuka }\end{array}$ & $\begin{array}{l}\text { Terjal, karang berpasir, } \\
\text { terbuka }\end{array}$ \\
\hline 4 & Curah hujan (mm/th) & $<2000$ & $2000-2500$ & $>2500$ \\
\hline 5 & Kondisi hidrologi & $\begin{array}{l}\text { Dekat dengan sungai } \\
\text { dan mencukupi }\end{array}$ & Dekat dengan sungai & $\begin{array}{l}\text { Jauh dari sungai dan } \\
\text { tingkat salinitas tinggi }\end{array}$ \\
\hline 6 & Jalur hijau (m) & $>100$ & $50-100$ & $<50$ \\
\hline 7 & $\mathrm{pH}$ tanah & $6,5-7,5$ & $5,5-6,5 \& 7,5-8,0$ & $<4,0-5,5 \& 8,0->9,0$ \\
\hline 8 & Penutupan lahan & $\begin{array}{l}\text { Belukar, tegalan, } \\
\text { tambak }\end{array}$ & Sawah, kebun & Mangrove, pemukiman \\
\hline
\end{tabular}

Sumber : [8][7][11]

Jumlah skor dari karakteristik parameter lahan tiap stasiun pengamatan sebagaimana dalam Tabel 1 kemudian dihitung sesuai dengan rumus:

$$
\text { Skor }=\frac{\text { Jumlah skor seluruh parameter }}{\text { Jumlah parameter }}
$$

Skor yang didapatkan adalah perbandingan antara jumlah skor seluruh parameter yang diukur di lapangan dengan jumlah seluruh parameter yang diukur. Hasil skor selanjutnya disesuaikan dengan keterangan kriteria daya dukung sesuai masing-masing. Mengacu pada pendapat para peneliti dengan hasil sebagaimana Tabel 1, kriteria daya dukung dan modifikasi dari pemberian skor sebagaimana Tabel 2.

Berdasarkan perhitungan skor dari masing-masing titik pengamatan terhadap pengukuran variabel maka lahan pesisir dengan skor 91 - 100 adalah lahan yang memiliki daya dukung yang baik. Skor $81-90$ memiliki daya dukung lahan sedang dan skor kurang dari 80 memiliki daya dukung lahan yang rendah. 
Tabel 2. Kriteria daya dukung

\begin{tabular}{lll}
\hline No & \multicolumn{1}{c}{ Skor } & \multicolumn{1}{c}{ Keterangan } \\
\hline 1. & $91-100$ & Daya dukung lahan baik \\
2. & $81-90$ & Daya dukung lahan sedang \\
3. & $\leq 80$ & Daya dukung lahan rendah \\
\hline
\end{tabular}

Hasil pengukuran terhadap parameter lahan pesisir, pengamatan secara visual di lapangan dan sumber data sekunder disajikan dalam Tabel 3.

\section{HASIL DAN PEMBAHASAN}

Tabel 3. Hasil pengukuran dan pengamatan terhadap lahan pesisir

\begin{tabular}{|c|c|c|c|c|c|c|c|c|}
\hline \multirow[b]{2}{*}{$\begin{array}{l}\text { No. } \\
\text { Sta. }\end{array}$} & \multicolumn{8}{|c|}{ Hasil pengukuran dan pengamatan } \\
\hline & $\begin{array}{l}\text { Tekstur } \\
\text { tanah }\end{array}$ & $\begin{array}{c}\text { Kelerengan } \\
\text { pantai } \\
(\%)\end{array}$ & $\begin{array}{l}\text { Tipe } \\
\text { pantai }\end{array}$ & $\begin{array}{l}\text { Curah } \\
\text { hujan } \\
(\mathrm{mm} / \mathrm{th})\end{array}$ & $\begin{array}{c}\text { Kondisi } \\
\text { hidrologi }\end{array}$ & $\begin{array}{c}\text { Jalur } \\
\text { hijau } \\
\text { (m) }\end{array}$ & $\underset{\text { tanah }}{\mathbf{p H}}$ & $\begin{array}{c}\text { Penutupan } \\
\text { lahan }\end{array}$ \\
\hline 1 & $\begin{array}{l}\text { Lempung } \\
\text { berpasir }\end{array}$ & 1,96 & $\begin{array}{l}\text { Landai } \\
\text { berpasir }\end{array}$ & 139,50 & $\begin{array}{c}\text { Dekat } \\
\text { sungai dan } \\
\text { mencukupi }\end{array}$ & $\begin{array}{c}>100 \\
\mathrm{~m}\end{array}$ & 6,8 & Tambak \\
\hline 2 & $\begin{array}{c}\text { Lempung } \\
\text { berpasir }\end{array}$ & 2,22 & $\begin{array}{c}\text { Landai } \\
\text { berlumpur }\end{array}$ & 193,08 & $\begin{array}{c}\text { Jauh dari } \\
\text { sungai }\end{array}$ & $50 \mathrm{~m}$ & 6,9 & Pemukiman \\
\hline 3 & $\begin{array}{l}\text { Lempung } \\
\text { berpasir }\end{array}$ & 2,19 & $\begin{array}{l}\text { Sangat } \\
\text { landai, } \\
\text { teluk }\end{array}$ & 144,92 & $\begin{array}{l}\text { Jauh dari } \\
\text { sungai }\end{array}$ & $\begin{array}{c}>100 \\
m\end{array}$ & 7 & Pemukiman \\
\hline 4 & $\begin{array}{l}\text { Lempung } \\
\text { berpasir }\end{array}$ & 2,03 & $\begin{array}{l}\text { Sangat } \\
\text { landai }\end{array}$ & 179,25 & $\begin{array}{c}\text { Dekat } \\
\text { sungai dan } \\
\text { mencukupi }\end{array}$ & $\begin{array}{c}>100 \\
\mathrm{~m}\end{array}$ & 7 & $\begin{array}{l}\text { Tambak, } \\
\text { belukar }\end{array}$ \\
\hline 5 & $\begin{array}{l}\text { Lempung } \\
\text { berpasir }\end{array}$ & 2,05 & $\begin{array}{l}\text { Landai, } \\
\text { teluk }\end{array}$ & 224,83 & $\begin{array}{c}\text { Dekat } \\
\text { sungai dan } \\
\text { mencukupi }\end{array}$ & $\begin{array}{c}>100 \\
\mathrm{~m}\end{array}$ & 6,8 & $\begin{array}{l}\text { Belukar, } \\
\text { sawah }\end{array}$ \\
\hline 6 & $\begin{array}{c}\text { Lempung } \\
\text { berpasir }\end{array}$ & 2,26 & Terjal & 102,17 & $\begin{array}{l}\text { Dekat } \\
\text { sungai }\end{array}$ & $75 \mathrm{~m}$ & 7 & Sawah \\
\hline 7 & $\begin{array}{l}\text { Lempung } \\
\text { berpasir }\end{array}$ & 2,33 & $\begin{array}{l}\text { Sangat } \\
\text { landai, } \\
\text { lumpur } \\
\text { berpasir }\end{array}$ & 250,42 & $\begin{array}{l}\text { Dekat } \\
\text { sungai }\end{array}$ & $\begin{array}{c}>100 \\
\mathrm{~m}\end{array}$ & 6,8 & Belukar \\
\hline 8 & $\begin{array}{l}\text { Lempung } \\
\text { berpasir }\end{array}$ & 1,88 & $\begin{array}{l}\text { Landai } \\
\text { berpasir }\end{array}$ & 143,08 & $\begin{array}{c}\text { Dekat } \\
\text { sungai dan } \\
\text { mencukupi }\end{array}$ & $\begin{array}{c}>100 \\
\mathrm{~m}\end{array}$ & 7 & $\begin{array}{c}\text { Kebun, } \\
\text { permukiman }\end{array}$ \\
\hline
\end{tabular}

Hasil pengamatan terhadap tektur tanah di sepanjang pesisir Kabupaten Jepara secara keseluruhan adalah lempung berpasir. Tekstur tanah merupakan perbandingan antara fraksi pasir, liat dan debu tanah [10]. Variasi dari sifat tanah tergantung pada tempat dan waktu yang disebabakan oleh hasil akhir dari proses yang terjadi secara internal/alami dan pengaruh luar. Pengaruh internal berkaitan dengan faktor geologi, hidrologi dan biolgi. Variasi sifat fisik tanah akibat dari proses alami yang dapat diregionalisasi dengan asumsi bahwa tempat yang berdekatan cenderung mirip atau mempunyai nilai yang tidak berbeda jauh [1]. Tekstur tanah yang baik untuk budidaya perairan adalah lempung liat berpasir. Hal ini untuk mendukung stabilitas konstruksi tambak yang baik. Untuk tekstur tanah lempung berpasir terdapat di lahan kecamatan Kedung, Jepara, Mlonggo dan Donorojo.

Kelerengan pantai diukur dengan menggunakan teodolit sehingga diperoleh elevasi lahan. Dari seluruh stasiun pengamatan diperoleh data kelerengan antara 1,88\% $2,33 \%$. Kelerengan sangat landai di bawah $2 \%$ adalah lahan di Kecamatan Kedung 1,96\% dan Kecamatan Donorojo sebesar 1,88\%. Triatmojo (1999) menjelaskan bahwa pantai berpasir memiliki kemiringan lahan antara $1 / 20$ dan $1 / 50$ di mana sudut kemiringan yaitu $\pm 0,5^{\circ}$.

Pengamatan terhadap seluruh stasiun, diperoleh data bahwa tipe pantai sangat beragam. Sebagian besar landai dengan substrat yang bervariasi, ada yang berpasir, berlumpur atau berlumpur dan berpasir. Satu lokasi yang tipe pantai terjal yaitu di 
Kecamatan Bangsri. Kondisi tipe pantai yang landai sangat mendukung bagi kegiatan budidaya di pesisir pantai yang dilakukan oleh kebanyakan masyarakat, karena berkaitan dengan inlet dan outlet saluran air tambak. Secara teknis, kegiatan budidaya memanfaatkan pasang surut. Pada saat pasang untuk memasukan air ke dalam tandon dan saat surut untuk mengeluarkan air ketika proses panen.
Data curah hujan tahun 2019 yang diperoleh dari BMKG Stasiun Klamotologi Semarang, menunjukkan bahwa secara umum curah hujan di kawasan pesisir Kabupaten Jepara berkisar antara 102,17 - 250,42 $\mathrm{mm} /$ tahun. Kisaran curah hujan secara keseluruhan pada tahun 2919 masih di bawah $2000 \mathrm{~mm} /$ tahun sehingga memiliki skor yang maksimal. Data lengkap curah hujan di seluruh kawasan pesisir Kabupaten Jepara sebagaimana Tabel 4.

Tabel 4. Data curah hujan tahun 2019 Kabupaten Jepara (mm/tahun)

\begin{tabular}{lrrrrrrrrr}
\multicolumn{1}{c}{ Bulan } & Kedung & $\begin{array}{c}\text { Tahu } \\
\text { nan }\end{array}$ & Jepara & Mlonggo & Bangsri & $\begin{array}{c}\text { Kem } \\
\text { bang }\end{array}$ & Keling & $\begin{array}{c}\text { Dono } \\
\text { rojo }\end{array}$ & $\begin{array}{c}\text { Rata2 } \\
\text { bulanan }\end{array}$ \\
\hline Januari & 537 & 834 & 674 & 939 & 1199 & 518 & 1523 & 950 & $\mathbf{8 9 6 , 7 5}$ \\
Pebruari & 153 & 398 & 352 & 231 & 387 & 212 & 272 & 43 & $\mathbf{2 5 6 , 0 0}$ \\
Maret & 436 & 437 & 287 & 451 & 370 & 230 & 508 & 242 & $\mathbf{3 7 0 , 1 3}$ \\
April & 254 & 245 & 141 & 133 & 248 & 128 & 270 & 219 & $\mathbf{2 0 4 , 7 5}$ \\
Mei & 47 & 76 & 96 & 146 & 43 & 19 & 106 & 98 & $\mathbf{7 8 , 8 8}$ \\
Juni & 0 & 0 & 0 & 0 & 0 & 0 & 0 & 8 & $\mathbf{1 , 0 0}$ \\
Juli & 0 & 0 & 0 & 0 & 0 & 0 & 0 & 1 & $\mathbf{0 , 1 3}$ \\
Agustus & 0 & 0 & 0 & 2 & 8 & 10 & 16 & 30 & $\mathbf{8 , 2 5}$ \\
September & 0 & 0 & 0 & 0 & 0 & 0 & 0 & 0 & $\mathbf{0 , 0 0}$ \\
Oktober & 0 & 0 & 0 & 0 & 0 & 0 & 0 & 12 & $\mathbf{1 , 5 0}$ \\
Nopember & 77 & 140 & 24 & 36 & 64 & 13 & 74 & 67 & $\mathbf{6 1 , 8 8}$ \\
Desember & 170 & 187 & 165 & 213 & 379 & 96 & 236 & 47 & $\mathbf{1 8 6 , 6 3}$ \\
\hline Rata-rata & $\mathbf{1 3 9 , 5 0}$ & $\mathbf{1 9 3 , 0 8}$ & $\mathbf{1 4 4 , 9 2}$ & $\mathbf{1 7 9 , 2 5}$ & $\mathbf{2 2 4 , 8 3}$ & $\mathbf{1 0 2 , 1 7}$ & $\mathbf{2 5 0 , 4 2}$ & $\mathbf{1 4 3 , 0 8}$ & \\
\hline
\end{tabular}

Sumber : [2]

Curah hujan berkaitan dengan suhu dan kelembaban udara di lokasi budidaya. Kegiatan budidaya memerlukan kestabilan suhu dan kelembaban untuk mengetahui bulan-bulan kering. Curah hujan yang tinggi menyebabkan suhu dan kelembaban menjadi tidak optimal untuk pengeringan tanah tambak. Pada Tabel 1 menunjukkan bahwa curah hujan sebesar $<2000 \mathrm{~mm} /$ tahun memiliki nilai skor tertinggi.

Keberadaan jalur hijau mempengaruhi keberadaan lahan budidaya. Lokasi yang memiliki jalur hijau tidak boleh dipergunakan untuk kegiatan budidaya. Hal ini untuk menjaga agar konservasi ekosistem penting di wilayah pesisir menjadi lebih terjaga. Hal itu ditunjukkan dengan pemberian bobot yang tinggi untuk jarak dengan jalur hijau lebih dari $100 \mathrm{~m}$ dan semakin dekat jalur hijau semakin rendah nilainya. Dari hasil pengamatan seluruh kawasan pantai Kabupaten Jepara cukup bervariasi. Kawasan yang jauh dari jalur hijau adalah Kecamatan Kedung, Jepara, Mlonggo, Bangsri, Keling dan Donorojo. Kawasan yang paling dekat dengan jalur hijau adalah Kecamatan Tahunan.

Kondisi hidrologi berkaitan dengan jauh dekatnya sungai yang memiliki air yang mencukupi. Wilayah kecamatan se-Kabupaten Jepara bervariasi kondisi sungainya, sebagian besar dekat dengan sungai yang memiliki air mencukupi. Ada dua wilyah yang jauh dari sungai yaitu Kecamatan Tahunan dan Jepara di Kecamatan Tahunan hampir tidak ada sungai besar yang bermuara di wilayah ini. Sedangkan di Kecamatan Jepara hanya terdapat 3 sungai sebagai kanal limpasan air hujan yang berlebihan, yaitu Kali Kanal, Kali Wiso dan Kali Sekembu. Ketiga sungai ini debit airnya cukup besar hanya pada saat musim penghujan namun sebaliknya pada musim kemarau. Ketiga sungai ini sangat berdekatan dengan wilayah pemukiman masyarakat.

Besaran $\mathrm{pH}$ tanah di seluruh kawasan pesisir Kabupaten Jepara hampir sama berkisar antara 6,8-7. Kondisi $\mathrm{pH}$ tanah ini cukup bagus unuk dijadikan kegiatan budidaya perairan. $\mathrm{pH}$ tanah berkaitan dengan unsur hara 
dan sifat-sifat tanah [6]. Potensi keasaman tanah yang tinggi dan $\mathrm{pH}$ tanah rendah menyebabkan kelarutan berbagai senyawa beracun menjadi lebih tinggi yang berdampak pada rendahnya ketersediaan unsur tertentu seperti fosfor [10].

Penutupan lahan kaitannya dengan kondisi eksisting lahan pada saat pengamatan. Kondisi penutupan lahan sepajang kawasan pesisir Kabupaten Jepara cukup bervariasi. Daerah tambak dan belukar yang merupakan lokasi dengan nilai skor tertinggi ada di Kecamatan Kedung, Mlonggo dan Keling. Sedangkan di tempat lain adalah sawah dan pemukiman. Kondisi penutupan lahan berkenaan dengan penggunaan lahan yang akan dibuka untuk kegiatan budidaya. Penutupan lahan oleh mangrove dan pemukiman merupakan lokasi yang paling sulit untuk dialihkan menjadi lokasi tambak. Sehingga nilai skor paling rendah dan selanjutnya adalah penutupan lahan oleh sawah dan kebun. Yang paling mudah untuk dialihkan menjadi kawasan tambak adalah lokasi dengan penutupan lahan berupa belukar, tegalan atau tambak itu sendiri.

Dari hasil tabulasi kondisi parameter lingkungan tiap stasiun pengamatan, kemudian dimasukkan dalam perhitungan skor dan diperoleh hasil sebagaimana Tabel 5.

Tabel 5. Skor dan kriteria untuk tiap lokasi

\begin{tabular}{clcc}
\hline $\begin{array}{c}\text { No. } \\
\text { Stasiun }\end{array}$ & $\begin{array}{c}\text { Lokasi/ } \\
\text { Kecamatan }\end{array}$ & Skor & Kriteria \\
\hline 1 & Kedung & 95,00 & Baik \\
2 & Tahunan & 87,50 & Sedang \\
3 & Jepara & 89,38 & Sedang \\
4 & Mlonggo & 98,13 & Baik \\
5 & Bangsri & 89,38 & Sedang \\
6 & Kembang & 86,88 & Sedang \\
7 & Keling & 89,38 & Sedang \\
8 & Donorojo & 91,88 & Baik \\
\hline
\end{tabular}

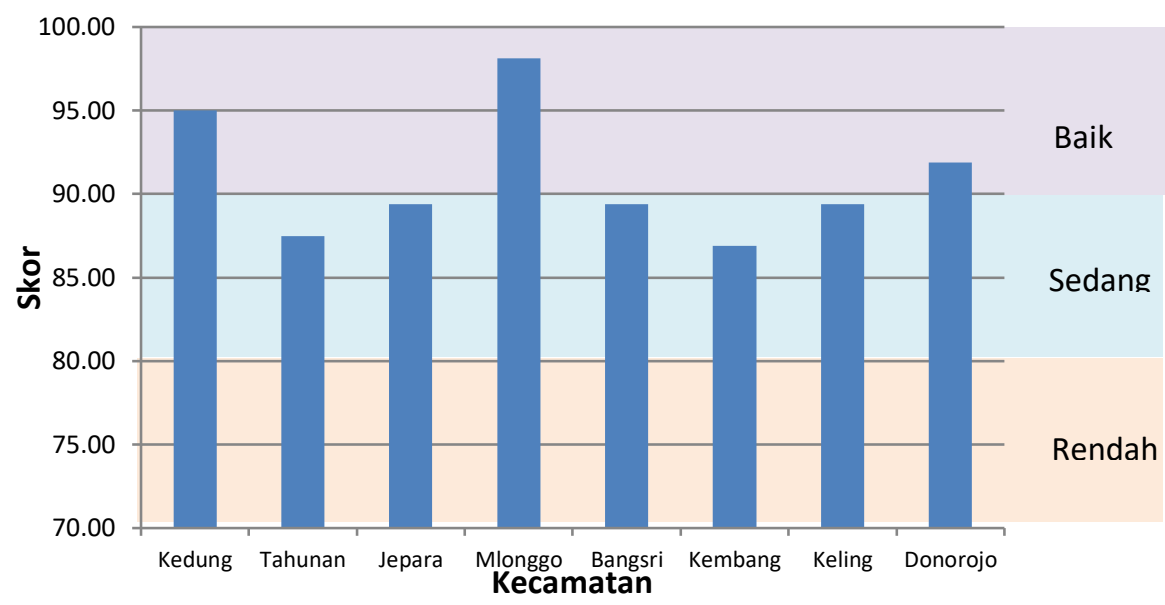

Gambar 2. Kategori berdasarkan kondisi lahan masing-masing lokasi kecamatan 


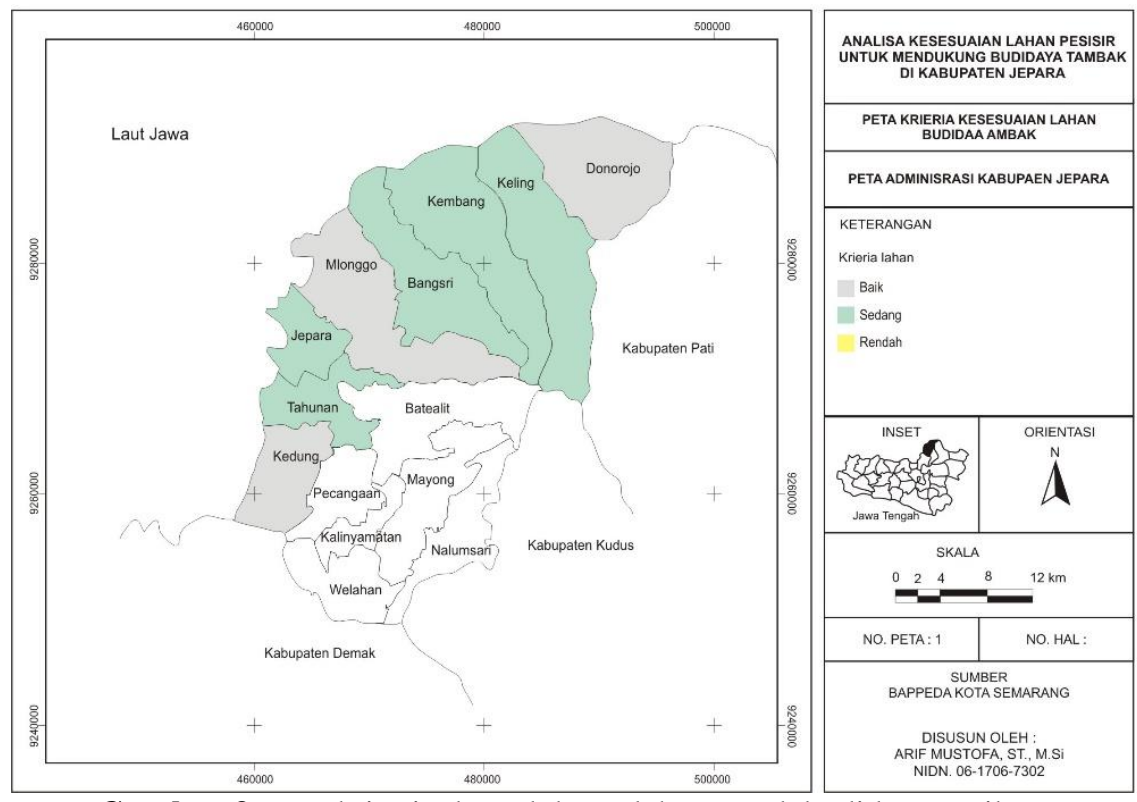

Gambar 3. Peta kriteria daya dukung lahan untuk budidaya perikanan

Pada Gambar 2 memberikan informasi grafis bahwa lahan pesisir Kabupaten Jepara hanya terdapat dua macam kriteria yaitu daya dukung lahan baik dan daya dukung lahan sedang. Pada gambar tersebut pula dapat diketahui bahwa lahan dengan kritria daya dukung lahan baik terdapat pada 3 kawasan saja yaitu Kecamatan Kedung, Mlonggo dan Donorojo. Sedangkan kawasan dengan kriteria daya dukung lahan sedang berada di Kecamatan Tahunan, Jepara, Bangsri, Kembang dan Keling. Lahan pesisir pada tiga kecamatan yang memiliki daya dukung baik yaitu Kedung, Mlonggo dan Donorojo memiliki karakteristik lahan yang tidak jauh berbeda.

Sebagaimana Gambar 3 tentang peta kriteria daya dukung lahan untuk budidaya perikanan di Kabupaten Jepara, dapat dijelaskan bahwa daya dukung lahan yang baik menurut skor terdapat di kawasan Kecamatan Kedung ditunjukkan dengan hasil pengukuran dan pengamatan terhadap curah hujan, kondisi hidrologi, jalur hijau, $\mathrm{pH}$ tanah dan penutupan lahan yang memiliki nilai skor tinggi. Sedangkan tekstur tanah, kelerengan pantai dan tipe pantai memiliki skor cukup rendah. Hasil perhitungan skor untuk Kecamatan Kedung adalah 95,00 yang berarti memiliki daya dukung baik. Untuk kawasan Kecamatan Mlonggo seluruh kriteria daya dukung memiliki skor yang tinggi kecuali tekstur tanah dan kelerengan pantai. Kedua kriteria ini memikiki nilai skor yang rendah, sehingga jumlah skor untuk Kecamatan Mlonggo adalah 98,13. Sedangkan kawasan Kecamatan Donorojo kriteria yang menyumbang skor tinggi adalah curah hujan, kondisi hidrologi, jalur hijau dan $\mathrm{pH}$ tanah. Sedangkan kriteria tekstur tanah dan tipe pantai menyumbang sekoro sedang dan paling rendah adalah kriteria kelerengan pantai dan penutupan lahan. Rata-rata skor di kawasan Kecamatan Donorojo adalah 91,88 yang berarti merupakan kriteria daya dukung yang baik untuk pengembangan budidaya perikanan tambak di Kabupaten Jepara.

Kawasan kecamatan lainnya memiliki kriteria daya dukung lahan sedang terhadap budidaya perikanan. Seluruh kriteria dalam lima kawasan ini memiliki skor daya dukung lahan sedang yaitu antara $81-90$, yang tinggi hanya kriteria $\mathrm{pH}$ tanah dan curah hujan. Nilai rata-rata paling rendah adalah 86,88 di Kecamatan Kembang dan tertinggi 89,38 di Kecamatan Jepara dan Kecamataan Keling. Kecamatan Bangsri, Kembang dan Keling secara ekologis memiliki kriteria yang sangat berbeda dengan kondisi di kecamatan lainnya yaitu penutupan lahan berupa hutan dan semak belukar akan tetapi kondisi hidrologisnya adalah jauh dari sungai.

\section{KESIMPULAN}


Berdasarkan analisis terhadap kesesuaian lahan pesisir, maka dapat disimpulkan bahwa wilayah pesisir Kabupaten Jepara memiliki karakteristik lahan yang memenuhi kriteria daya dukung lahan baik terhadap budidaya perikanan adalah wilayah pesisir Kecamatan Kedung, Mlonggo dan Donorojo. Kriteria daya dukung sedang adalah wilayah pesisir Kecamatan Tahunan, Jepara, Bangsri, Kembang dan Keling. Tidak ditemukan kriteria daya dukung lahan rendah di wilayah pesisir Kabupaten Jepara.

\section{UCAPAN TERIMA KASIH}

Terima kasih kepada Direktorat Riset dan Pengabdian Masyarakat Deputi Bidang Penguatan Riset dan Pengembangan Kementerian Riset dan Teknologi/Badan Riset dan Inovasi Nasional dan Lembaga Penelitian dan Pengabdian kepada Masyarakat UNISNU Jepara yang telah memberikan kesempatan untuk melakukan penelitian pada skim Penelitian Dosen Pemula tahun 2020.

\section{DAFTAR PUSTAKA}

[1] Agus, F., Yusrial, dan Sutono. 2006. Penetapan Tekstur Tanah dalam Sifat Fisik Tanah Dan Metode Analisisnya. Balai Besar Litbang Sumberdaya Lahan Pertanian. Kurnia, Bogor.

[2] Badan Meteorologi, Klimatologi dan Geofisika (BMKG) Stasiun Klimatologi Semarang. 2020. Informasi Curah Hujan Bulanan Wilayah Kab. Jepara Periode Tahun 2019.

[3] Bose, A.N., Ghosh, S.N., Yang, C.T., \& Mitra, A. 1991. Coastal Aquaculture Engineering. Oxford \& IBH Publishing Co. Pvt. Ltd., New Delhi. 365 pp.

[4] Cahyanto, N.P., H Setiyono dan E. Indrayanti. 2014. Studi Profil Pantai di Pulau Parang Kepulauan Karimunjawa Jepara. Jurnal Oseanografi. Volume 3, Nomor 2, Tahun 2014, Halaman 161166

[5] Mardiatno, D., B. Susilo dan E.T W. Mei. 2018. Potensi Sumberdaya Pesisir
Kabupaten Jepara. Gadjah Mada University Press. Yogyakarta.

[6] Nazir, M., Syakur dan Muyassir. 2017. Pemetaan Kemasaman Tanah dan Analisis Kebutuhan Kapur di Kecamatan Keumala Kabupaten Pidie. Jurnal Ilmiah Mahasiswa Pertanian Unsyiah Volume 2, Nomor 1, Februari 2017, Halaman 21-30.

[7] Poernomo A. 1992. Pemilihan Lokasi Tambak Udang Berwawasan Lingkungan. Pusat Penelitian dan Pengembangan Perikanan Badan Penelitian dan Pengembangan Pertanian. Jakarta.

[8] Purnomo, A., R. Hartono dan B.S. Wiwoho. 2011. Identifikasi dan Invenatrisasi Potensi Lahan Tambak di Wilayah Pesisir Kabupaten Lumajang. Jurnal Pendidikan Geografi Th. 16 No. 1 Januari 2011: 77 - 84 .

[9] Rachmansyah dan A. Mustafa. 2011. Evaluasi Kesesuaian Lahan Aktual Tambak Yang Ada di kabupaten Tanjung Jabung Barat Provinsi Jambi. J. Ris. Akuakultur. Vol. 6 No. 2 Tahun $2011: 311-324$.

[10] Ratnawati E. dan A. I. Asaad. 2012. Daya Dukung Lingkungan Tambak di Kecamatan Pulau Derawan dan Sambaliung, Kabupaten Berau, Provinsi Kalimantan Timur. Jurnal Ilmiah Perikanan dan Kelautan Vo. 4 No. 2, November 2012, hal. 175 - 185.

[11] Ristiyani, D. 2012. Evaluasi Kesesuaian Lahan Untuk Budidaya Perikanan Tambak Di Pesisir Kendal. Jurnal Geo Image 1 (1) 2012 : 12-18

[12] Triatmojo, B., 1999. Teknik Pantai. Beta offset. Yogyakarta.

[13] Triyatmo, B. 2001. Studi Kesesuaian Lahan Pesisir Untuk Tambak di Kecamatan Ngombol Kabupaten Purworejo. Jurnal Perikanan UGM (GMU J. Fish. Sci.) III (2) : $19-26$. 